\title{
Le Journal est mort. Vive le Journal!
}

\author{
Douglas W. Canfield \\ Coordinator III, Language Resource Center \\ The University of Tennessee \\ Managing Interim Co-Editor, IALLT
}

Far from being a trite inauguration of a new era for IALLT scholarship (or death by epanalepsis), this somewhat clichéd title serves as a proclamation that IALLT will never be without a journal, it has just been "in absentia" for a few months. Just as it took Edward I of England time to return from the Crusades to assume his duties as successor to his father, Henry III, so it has taken the IALLT Board and staff of the IALLT Journal time to make sure that the Journal's metamorphosis was proper, and allowed room for the Journal to continually grow and expand as technologies do. We appreciate your patience and understanding, and proudly present you with Volume 39 of the IALLT Journal of Language Learning Technologies, our first foray into the realm of digital scholarship.

This volume represents an ongoing commitment to bring the praxis of IALLT scholarship into harmony with what we preach and promote as a body of language instructional technologists. While this first step - switching from a print format to an online digital format - seems a small one, it is significant in that IALLT is collaborating with Martin Holmes of the Humanities Computing and Media Centre at the University of Victoria to leverage a new system for electronic publishing that provides both online and print versions of a journal from a single source, in a highly-configurable system, based on guidelines from the Text Encoding Initiative (TEI) Consortium, guidelines that IALLT is helping to define in this collaboration.

The TEI journal system that IALLT has adopted (for what is affectionately being called IALLTJ 1.5) lays the groundwork for significant changes to the IALLT Journal in the near future, as the direct incorporation of rich media and Web 2.0 collaborative tools into the Journal real estate becomes a reality, and holds promise for the facilitation of discussion, dialogue and interaction among authors and readers in a way heretofore unseen. We're not at IALLTJ 2.0 yet, but I am excited by what the future holds as the Journal moves in that direction. As you already know, the Journal has its own home (www.ialltjournal.org) to make possible the kind of interactivity and incorporation of rich media that the IALLT leadership sees in the future of the Journal.

The switch from print scholarship to digital scholarship also has ramifications for how we distribute our content to the worldwide scholarly community via libraries and institutions. Heather McCullough and I along with the IALLT Board have sought out and will soon have a structure in place that allows for a globally distributed online solution and standard access platform to allow libraries and institutions to 
subscribe and have access to the digital Journal.

This effort of bringing a new iteration of the Journal into being is the direct product of several people, who deserve recognition and my heartfelt thanks for their association. First, the entire IALLT Board, whose vision for the future of this journal and the organization is remarkable. Next, Martin Holmes, whose expertise with the TEI XML and his willingness to be a teacher, listener, and at times a third editor was as invaluable as the tool he is building for us. Finally, my colleague and co-editor Heather McCullough, who has proven to be the consummate editor, manager and motivator, and the nicest person there could be to work with on this project.

Of course, all of these efforts would be in vain without the efforts of those of you who decide not to cling fondly to your papers, reports and ideas, but to submit them for publication. Much as the authors of the excellent articles you will find in this volume, you are doing work that could directly benefit many, and you deserve to be recognized for your innovations. Take a look at the Publishing Guidelines and consider submitting something for a future issue. For those of you who will be attending the CALICO/IALLT joint meeting in March 2008 (https://www.calico.org/conference/index.php), make sure to attend the session entitled "How to Get Published in the IALLT Journal: Advice from the Editors", where we will go into detail about guidelines and suggestions, answer all questions, and be available for those who want to "bounce ideas" off of us. Of course, you don't have to wait to do that...you can do that anytime by e-mailing us at editor@ialltjournal.org. 